\title{
Evaluation of Extracellular Organic Matter from Micrococcus luteus Effects on Hydrocarbon-Degrading Bacterial Communities
}

\author{
Naila Bounedjoum ${ }^{1,2}$, Attila Bodor ${ }^{1,2,3}$, György Erik Vincze1, Krisztián Laczi ${ }^{1}$, Katalin Perei1,2 and Gábor \\ Rákhely ${ }^{1,2,3}$ \\ ${ }^{1}$ Department of Biotechnology, University of Szeged, Hungary \\ Közép fasor 52., H-6726 Szeged, Hungary \\ ${ }^{2}$ Institute of Environmental and Technological Sciences, University of Szeged, Hungary \\ Közép fasor 52., H-6726 Szeged, Hungary \\ ${ }^{3}$ Institute of Biophysics, Biological Research Centre, Szeged, Hungary \\ Temesvári krt. 62., H-6726 Szeged, Hungary
}

\section{Extended Abstract}

Bioremediation proved to be one of the most cost-effective and ecofriendly tool to rehabilitate hydrocarboncontaminated environments [1]-[3]. This biotechnology is controlled by various optimal environmental and biological factors specific to each site.

One of the keys to an efficient bioremediation of long term hydrocarbon-contaminated environments is the growth and the survival of the indigenous potential hydrocarbon-degrading microbial communities and their access to the contaminants. Only a small fraction of the native microflora can be cultivated and characterized using culture-dependent methods; most of these microorganisms remain unrecovered. To cope with a stressful environment, the yet-to-be-cultured bacterial strains frequently adopt a survival strategy, known as the viable but non-culturable state (VBNC). The VBNC bacteria can revert from this state through a resuscitation process when environmental conditions are favorable again, or triggered by resuscitation promoting factors (Rpfs) such as found in the extracellular organic matter (EOM) of Micrococcus luteus [4].

Lubricating oils (LOs) and Used Lubricating Oils (ULOs) are widespread hazardous pollutants of a varying chemical formulation, they consist of a complex mixture of linear, branched and cyclic alkanes, mono and polyaromatics, additives and an increased fraction of heavy metal after usage[5][6]. Therefore, these xenobiotics are crucial targets of the environmental processes and pollution research.

In the present study, we aimed to investigate the indigenous bacterial communities' composition and diversity as well as their hydrocarbon degrading abilities in response to EOM from M. luteus.

To achieve our goals, hydrocarbons-degrading consortia were recovered from the maintenance area of a train station oil-contaminated soil. The indigenous enrichment cultures were characterized and the EOM effect on the diversity and composition of the bacterial communities was evaluated using next generation sequencing methods (NGS). The enrichment cultures' biodegradation efficiency in response to EOM was assessed in aqueous matrices supplemented with LO and Artificial Diesel Oil (ADO).

Our preliminary results suggest that EOM could increase the relative abundance of genera previously reported to be predominant in bioremediation of aromatics and long term hydrocarbon-contaminated sites, such as, Acinetobacter, Chryseobacterium, Pseudomonas [7] and hence, potentially enhanced the bioconversion efficacy. The EOM treated groups had higher fractions of uncultured bacteria and minor groups, suggesting so, an increased bacterial diversity. Moreover, EOM addition significantly promoted the enrichment cultures' hydrocarbon-degrading efficiency compared to the nonsupplemented groups. The observed trend could be attributed to the enhanced relative abundance of the well-known genera with outstanding degradation capabilities as well as the uncultured fraction potentially enclosing effective yet-to-be cultured hydrocarbon degraders. 


\section{Acknowledgements}

The project was supported by the European Union and Hungarian State (grant agreement no. EFOP-3.6.2-162017-00010) and by the Norway Grant (grant agreement no. HU09-0044-A1-2013).

\section{References}

[1] C. Lors, A. Ryngaert, F. Périé, L. Diels, and D. Damidot, "Evolution of bacterial community during bioremediation of PAHs in a coal tar contaminated soil," Chemosphere, vol. 81, no. 10, pp. 1263-1271, 2010.

[2] S. Kuppusamy, N. R. Maddela, M. Mallavarapu, and K. Venkateswarlu, Total petroleum hydrocarbons. Environmental fate, toxicity, and remediation. Springer International Publishing, 2020.

[3] N. Meeboon, M.-C. Leewis, S. Kaewsuwan, S. Maneerat, and M. B. Leigh, "Changes in bacterial diversity associated with bioremediation of used lubricating oil in tropical soils.," Arch. Microbiol., vol. 199, no. 6, pp. 839851, Aug. 2017.

[4] H. S. Xu, N. Roberts, F. L. Singleton, R. W. Attwell, D. J. Grimes, and R. R. Colwell, "Survival and viability of nonculturable Escherichia coli and Vibrio cholerae in the estuarine and marine environment," Microb. Ecol., vol. 8, no. 4, pp. 313-323, Dec. 1982.

[5] R. Vazquez-Duhalt, "Environmental impact of used motor oil," Science of the Total Environment, The, vol. 79, no. 1. pp. 1-23, 1989.

[6] S. Kuppusamy Kuppusamy, N. R. Maddela, M. Mallavarapu, K. Venkateswarlu, S. Kuppusamy, N. R. Maddela, M. Megharaj, K. Venkateswarlu, "An Overview of Total Petroleum Hydrocarbons," in Total Petroleum Hydrocarbons, Springer International Publishing, 2020, pp. 1-27.

[7] X. M. Su, Y. D. Liu, M. Z. Hashmi, L. X. Ding, and C. F. Shen, "Culture-dependent and culture-independent characterization of potentially functional biphenyl-degrading bacterial community in response to extracellular organic matter from Micrococcus luteus," Microb. Biotechnol., vol. 8, no. 3, pp. 569-578, May 2015. 